\title{
AS INVESTIGAÇÕES INTERNAS E A ANÁLISE ECONÔMICA DO DIREITO
}

\author{
INTERNAL INVESTIGATIONS AND ECONOMIC ANALYSIS OF LAW
}

\author{
Fábio André Guaragni ${ }^{1}$ \\ Lourenço de Miranda Freire Neto ${ }^{2}$ \\ Douglas Rodrigues da Silva ${ }^{3}$
}

\begin{abstract}
RESUMO
O presente artigo tem por escopo perquirir em que medida as investigações internas empresariais se relacionam com a análise econômica do direito. Para tanto, far-se-á, de início, um breve estudo sobre o que se entende por análise econômica do direito, apurando suas origens e nuances específicas, bem como a utilização do método econômico na ciência jurídica. Adiante, especificamente no campo das investigações internas, buscar-se-á a contextualização dos mecanismos privados de investigação de ilícitos e, sobretudo, a sua feitura diante de um novo quadro normativo em que a colaboração da pessoa jurídica ganha relevo na fixação das sanções e, principalmente, no que se refere à reputação da empresa diante do mercado e da sociedade. Ao final, tendo em vista os preceitos da análise econômica do direito, relacionar-seá as investigações internas aos métodos econômicos de adoção de medidas jurídicas por parte das pessoas jurídicas.
\end{abstract}

Palavras-chave: análise econômica do direito; investigações internas; compliance.

\begin{abstract}
The purpose of this article is to investigate the extent to which internal business investigations are related to the economic analysis of law. To this end, a brief study will be made at the beginning of what is understood by economic analysis of law, investigating its origins and specific nuances, as well as the use of the economic method in legal science. Ahead, specifically in the field of internal investigations, we will seek to contextualize the private mechanisms for investigating illicit acts and, above all, their creation in the face of a new normative framework in which the collaboration of the legal entity gains prominence in the establishment of sanctions and , mainly, with regard to the company's reputation in the market and society. In the end, in

1 Doutor em Direito pela Universidade Federal do Paraná (UFPR). Mestre em Direito pela Universidade Federal do Paraná (UFPR). Docente Permanente do Programa de Pós-Graduação em Direito do Centro Universitário Curitiba - UNICURITIBA. Procurador de Justiça no Estado do Paraná.

2 Doutorando em Direito Político e Econômico pela Universidade Presbiteriana Mackenzie -UPM. Mestre em Direito pela Universidade Católica de Pernambuco. Bacharel em Direito pela Universidade Federal da Paraíba. Professor e Advogado.

3 Mestrando em Direito Empresarial e Cidadania pelo Centro Universitário Curitiba - UNICURITIBA. Especialista em Direito Penal e Processo Penal pelo Centro Universitário Curitiba - UNICURITIBA. Professor de Direito Penal Econômico e Legislação Penal Especial nas Faculdades da Indústria de São José dos Pinhais (FIEPIEL). Advogado Criminal.
\end{abstract}


view of the precepts of the economic analysis of law, internal investigations will be related to the economic methods of adopting legal measures by legal entities.

Keywords: economic analysis of law; internal investigations; compliance.

\section{INTRODUÇÃO}

As escolhas individuais, sobretudo naquilo que se relacionam às consequências jurídicas de determinada conduta, passam, segundo alguns, por uma criteriosa análise de custos e benefícios da ação a ser tomada. A adoção racional de tal ou qual atitude, em certos contextos, pode estar muito mais relacionada à reflexão das consequências negativas ou positivas do que em efetivo às imposições cruas da norma jurídica. Com efeito, a partir da transposição dos métodos da ciência econômica, é possível perquirir se uma ação concreta, vista sob o ponto de vista jurídico, pode ser lida como eficiente e benéfica ao sujeito que a pratica. E é justamente nesse ponto que ganha especial relevância no estudo dos fenômenos jurídicos a denominada Análise Econômica do Direito.

Olhando-se para os objetivos deste trabalho de pesquisa, o que se busca, ao fim e ao cabo, é perquirir justamente em que medida as investigações internas empresariais, nas quais a própria pessoa jurídica se encarrega de apurar a prática de ilícitos em sua esfera organizacional, pode ser vista sob o enfoque da Análise Econômica do Direito. Noutros termos, a intenção é apurar a possível relação entre a adoção de mecanismos próprios de apuração dos atos ilícitos ocorridos no interior da empresa e, na sequência, a entrega desse material às autoridades públicas; com os eventuais benefícios ofertados pela legislação à pessoa jurídica colaboradora (ou leniente) e se tal opção jurídica pode ser vista como uma escolha racional baseada em métodos econômicos.

Assim, visando responder a indagação proposta, no primeiro capítulo da pesquisa será abordada de maneira um pouco mais detida o conceito e as principais nuances da denominada Análise Econômica do Direito, as origens do método, seus principais precursores e, principalmente, os seus métodos de análise do direito, delineando os pontos essenciais. $\mathrm{Na}$ sequência, adentrando no campo das investigações internas, o segundo capítulo abordará o que se entende por investigações internas, as suas principais características e a sua inserção no ordenamento jurídico brasileiro a partir da Lei Anticorrupção, em especial os eventuais benefícios que podem ser concedidos à pessoa jurídica que adota postura colaborativa na colheita e apresentação de elementos informativos e de prova às autoridades públicas. Por 
último, considerando os principais aspectos das investigações internas e os preceitos da análise econômico do direito, será analisada a relação entre ambas e se a opção por mecanismos privados de investigação pode ser vista como uma escolha eficiente na esfera da Análise Econômica do Direito.

\section{O DIREITO VISTO SOB O PRISMA DA CIÊNCIA ECONÔMICA: A ANÁliSE ECONÔMICA DO DIREITO}

À primeira vista, torna-se bastante confuso tentar compreender que o direito, enquanto ciência do dever ser, possa se relacionar estritamente com os aspectos mais específicos das ciências econômicas, cujo objeto e método costumam passar por caminhos amplamente diversos se postos em comparação aos mecanismos jurídicos de análise e compreensão da realidade.

O direito, se visto sob a compreensão cunhada por Kelsen (1992, p. 22), tem por fim motivar o indivíduo a adotar determinada conduta com pretensão de reciprocidade dos demais membros da sociedade ao mesmo tempo que indica a proibição de certos atos lesivos e indesejáveis, tudo isso a partir de um princípio de recompensa ou punição, sendo, antes de tudo, uma ordem social coercitiva. Norberto Bobbio (2012, p. 25-28), partindo do prisma normativo, também compreende que o direito é uma regra de conduta, mas que deriva de uma norma que nos é imposta, indicando que a liberdade plena por nós imaginada desde o nascedouro, em verdade, é guiada do princípio ao fim pela teia normativa que nos rodeia. O direito, no seu entender, seria parte exuberante e visível de uma grande experiência normativa a que estamos submetidos, em que nosso comportamento é diretamente influenciado para uma direção ou outra.

Já a economia debruça-se sobre o estudo dos denominados fenômenos da produção, indicando de que maneira se torna mais eficiente e maximizada a alocação de recursos escassos e finitos, sempre no intento de se alcançar o melhor resultado possível diante das necessidades humanas (GONÇALVES; STELZER, 2012, p. 78). É dirigida, antes de tudo, ao pensar eficiente dentro da otimização de custos e benefícios de determinada ação concreta.

Olhando-se assim parece bastante tormentoso, num primeiro momento, relacionar uma e outra ciência, com suas peculiaridades e métodos próprios, como se estivessem entrelaçadas e ligadas numa relação de interdependência. Enquanto uma ciência termina por ser restrita ao aspecto positivo-normativo de uma ordem social, a outra visa desenvolver condições de futuro 
a partir da eficiência das decisões presentes. Mas o conflito é apenas aparente. No âmbito da ciência econômica, e aqui merece destaque a obra de Karl Marx, direito e economia interagem na medida em que o fenômeno econômico é ponto central e determinista das estruturas sociais, constituindo-se, no seu dizer, numa superestrutura com capacidade de influenciar e indicar os rumos do direito e das demais instituições (VIEIRA, 1996, p. 31). Ou seja, o direito pode até ser uma ordem coercitiva, mas é uma ordem coercitiva determinada pelo fenômeno econômico. A interação entre direito e economia também pode ser vista sob a perspectiva de Stammler, em que o direito ora cria o fato econômico ora é determinado por ele. Certo é que direito e economia, num ponto ou outro, se aproximam e se encontram no desenrolar do estudo e análise dos fenômenos sociais, sendo incontestável sua interação, como bem observam Stelzer e Gonçalves (2012, p. 78-79).

E é justamente aí que ganha especial relevo aquilo que se convencionou chamar de Law and Economics (LaE) ou, entre nós, de Análise Econômica do Direito (AED).

Tal pensamento, originado em trabalhos formulados por Ronald Coase e, sobretudo, Richard Posner, expoentes da denominada Escola Econômica de Chicago, nas décadas de 60 e 70 do século XX - então um movimento de reação ao modelo de new deal -, tinha por direção a aplicação de categorias e teorias próprias das ciências econômicas no estudo e perquirição dos fenômenos jurídicos da sociedade (ALVAREZ, 2006, p. 52), rompendo com os meios tradicionais de estudo da realidade jurídico-social. Muito longe de se configurar num transporte puro e simples de meios e institutos da teoria econômica, a AED visa desenvolver uma análise da eficiência do direito a partir daquilo que Gonçalves e Ribeiro (2013, p. 81) chamam de "ferramentas epistemológicas" não oriundas nem do direito e nem da economia, mas da aproximação de ambas. É, antes de mais nada, uma proposição de estudo multidisciplinar elegendo a teoria econômica como referencial analítico (ALVAREZ, 2006, p. 53), até mesmo porque considera que o direito não é uma realidade autônoma.

Como asseveram Gonçalves e Stelzer (2012, p. 87):

\footnotetext{
A LaE busca a compreensão do universo jurídico partindo de pressupostos e valores metajurídicos pertencentes ao mundo do econômico, aplicáveis, tanto quando da criação da norma jurídica como quando de sua verificabilidade, já em instância de caso concreto, nas barras dos tribunais. Entende-se, pois, que a prática jurídicoeconômica de mercado, como discurso vigente, deve fazer refletir fenômeno jurídicosocial conforme realidade inevitável e inarredável da previsão legal segundo critérios racional-normativos de maximização de lucros - riqueza - e de eficiência econômica que ocorram dentro de uma dialética social-econômico-normativa construtiva.
} 
A AED, noutros termos, buscou demonstrar - e estender - a racionalidade atribuída aos fenômenos do mercado, seus esquemas de análise e critérios de tomada de decisão como referência no estudo de campos que transcendem aqueles eminentemente econômicos (HAMMAN, 2012, p. 106), dos quais o direito pode ser visto com um dos focos principais.

Por outro lado, a AED exige determinadas premissas para que possa ser vista como referencial de análise do direito.

\subsection{AS PREMISSAS PARA UMA ANÁLISE ECONÔMICA DO DIREITO}

Nas lições de Gonçalves e Ribeiro (2013, p. 81), a AED parte de dois estratos epistemológicos distintos no que se refere à interação entre a ciência jurídica e a ciência econômica. Há um ponto de análise descritiva ou positiva, em que o campo de pesquisa acaba por se concentrar nos reflexos práticos que o direito exerce na realidade fática; assim como há uma espécie de análise normativa, na qual o ponto de debates se fixa na análise do conceito de justiça e, sobretudo, da sua relação com as ideias de eficiência da teoria econômica, sendo uma vertente propositiva. $\mathrm{O}$ enfoque, de maneira geral, passa a ser não só o estudo dos efeitos das normas positivas como também os seus desdobramentos dentro da ótica de custos e efeitos mercadológicos e econômicos, principalmente no processo de tomada de decisões, assumindo um viés de cunho "consequencialista" muitas vezes. Ou, como destaca Alvarez (2006, p. 58), "A novidade da AED é dar uma fundamentação econômica à teoria do direito e, neste sentido, mas que se centrar nos efeitos das normas, terá que se centrar na eficiência e, portanto, no princípio da maximização".

Para se compreender a AED, todavia, tem que se ter em mente que seu objeto não visa limitar o direito à economia, muito menos alterar as categorias e institutos jurídicos consagrados àqueles que são comuns às ciências econômicas. A questão vai muito além. Sobretudo sob o aspecto descritivo (ou positivo), o foco da AED está concentrado no processo de tomada de decisões e nas consequências que tal ou qual caminho escolhido ensejará, especialmente no que atine à eficiência e à maximização dos recursos, tudo com vistas não a indicar aquele que possa ser o caminho mais justo - até mesmo pela amplitude axiológica do conceito de justiça -, mas talvez como meio de identificação daquilo que não se enquadre como medida justa, porquanto repudia o desperdício e o alto custo de uma regra jurídica (GONÇALVES; RIBEIRO, 2013, p. 86). 
Partindo-se dessas considerações, de início, já se pode compreender a primeira premissa necessária à aplicação da AED: a construção do indivíduo - o tomador de decisões - como um ser racional e, principalmente, com interesses e anseios próprios dos quais pretende retirar o máximo proveito. Ou seja, aqui “Os atores são racionais e suas ações são pautadas por cálculos de custos e benefícios de acordo com seus interesses ou preferências" (RIBEIRO; CAIADO, 2015, p. 251).

Como explica Alvarez (2006, p. 51):

[...] para a AED os indivíduos são criaturas racionais que se comportam tentando maximizar seus interesses em todos os âmbitos e facetas da vida, razão porque na perspectiva econômica o direito é um conjunto de incentivos que premia condutas eficientes e penaliza as ineficientes $[\ldots]$.

Ou seja, justamente por ser um sujeito racional, com capacidade de definir anseios e interesses, é que o indivíduo ao tomar uma decisão pode saber se prefere um ou outro caminho posto à sua disposição. E é nesse processo de tomada de decisão, baseado em preferências de maximização e eficácia, que aparece a ideia de incentivo e penalização das quais uma das principais formas apresentadas ao indivíduo costuma ser justamente a norma jurídica (GONÇALVES; RIBEIRO, 2013, p. 82). É dizer: muito distante da ideia de correção, a adoção (ou escolha) racional de um comportamento definido numa norma jurídica está muito mais ligada à noção de custos e benefícios a fim de aumentar o nível de satisfação de quem o elege, esperando, assim, que a escolha de uma conduta - inclusive aquela descrita numa norma apresente, como consequência, um resultado mais benéfico do que os seus eventuais custos (LARA, 2009). Ou, como exemplificado por Gonçalves e Ribeiro (2013, p. 82), “A norma jurídica e, principalmente, a sua sanção, é processada como um preço pelo seu destinatário".

Este sujeito constituído sob o manto da escolha racional convencionou-se denominar homo oeconomicus. É a partir dele que se pode inicialmente buscar a compreensão da AED. Mas é evidente que a figura do homo oeconomicus não se restringe à escolha racional, ela corresponde apenas ao ponto de partida.

O indivíduo, sob o prisma da AED, não só faz escolhas racionais - e isso está implícito no conceito de escolha formulado - como também visa maximizar os seus interesses e preferências. E é a partir do momento que todos os indivíduos alcançam um padrão interativo decorrente da maximização simultânea de suas preferências que se pode afirmar a existência de um equilíbrio (LAUDA, 2009, p. 12-13). Desse equilíbrio, em que nenhuma utilidade 
individual poderá ser incrementada sem o decréscimo de outra, que decorre o chamado Ótimo de Pareto, quando então poderá se falar em eficiência.

Porém, em termos práticos, a ideia de Ótimo de Pareto é alvo de severas críticas, porquanto relações interativas entre indivíduos não costumam permanecer restritas e, comumente, atingem interesses e preferências de terceiros, sendo difícil ilustrar qualquer transação - como a introdução de determina norma jurídica numa realidade concreta - que não envolva, de alguma parte, um prejuízo, mesmo que reflexo, a uma terceira pessoa (GONÇALVES; RIBEIRO, 2013, p. 83).

Por isso mesmo um dos critérios de eficiência com maior aceitação no âmbito da AED - e adotado aqui - se refere à concepção de Kaldor-Hicks. Sob tal ótica, entende-se a eficiência a partir de um cálculo racional em que os ganhos advindos da conduta adotada, sempre objetivando o máximo bem-estar, compensem as perdas que porventura sejam dela derivadas. A ação intenta gerar o máximo de ganho para o maior número de pessoa. Como aduz Tabak (2015, p. 324), “A introdução de uma norma jurídica gera benefícios para alguns agentes e custos para outros agentes. Caso o benefício total seja maior que o custo total da introdução de determinada norma, essa é eficiente no sentido de Kaldor-Hicks".

Nas ilações de Ribeiro e Campos (2012, p. 318):

\begin{abstract}
Melhor explicitando, quanto maior for a convicção do indivíduo de que a aplicação da norma jurídica irá aumentar seus prejuízos (gasto de dinheiro, matéria-prima, tempo...), maior será o efeito da norma na escolha de suas condutas, pois, sendo ele racional, irá orientar a escolha de seu comportamento pela opção que lhe pareça mais benéfica, numa análise de custo e benefício.
\end{abstract}

Nesse contexto, pois, partindo-se de um exame pautado pela AED, a norma jurídica deve ser vista dentro de uma ótica dos pressupostos econômicos, sendo vista como eficiente e adequada quando, na hipótese concreta, trabalhe no sentido de facilitar e dar fluidez às relações econômicas, objetivando, antes de mais nada, a busca pela maximização do lucro e otimização na produção. Dito de outro modo, a norma jurídica - sobretudo aquelas relacionadas aos atores da produção - deve ser analisada sob o parâmetro da realidade social econômica, qual seja, o mercado. Assim, o que interessa, efetivamente, não é o cariz coercitivo da norma jurídica, como costuma-se trabalhar no mundo jurídico, mas o direito como um meio influenciador na escolha de ações individuais dentro de um critério de custo/benefício, tornando-se um fator determinante na adoção de comportamentos sociais (GONÇALVES; STELZER, 2012, p. 87$88)$. 
E é este parâmetro de análise, em linhas gerais, o critério padrão de análise dos mecanismos de investigação interna corporativa, ponto fulcral da presente pesquisa.

\section{UMA INCURSÃO NAS INVESTIGAÇÕES INTERNAS EMPRESARIAIS: A ADOÇÃo DE CONDUTAS PERSECUTÓRIAS PELA PRÓPRIA PESSOA JURÍDICA}

Já adentrando no segundo estrato da pesquisa, especificamente sobre as investigações internas empresariais, o que se buscará, primordialmente, é a relação de sua adoção, enquanto mecanismo privado de investigação e arrecadação de elementos informativos por parte da própria pessoa jurídica onde se originou determinado ato ilícito, com os critérios de escolha racional derivados das premissas da Análise Econômica do Direito. É dizer: a partir dos preceitos da AED, intentar-se-á encontrar a relação existente entre as condutas adotadas pela própria empresa, a fim de investigar e entregar às autoridades públicas fatos e provas acerca de ilícitos praticados por ela própria ou no seu interesse, diante das consequências jurídicas que poderão advir dos diplomas normativos anticorrupção, em que há previsão expressa de responsabilização jurídico-administrativa - somada, por evidente, a outras esferas de responsabilidade, inclusive extrajudicial.

É, em suma, o objetivo desta segunda parte do trabalho.

Por isso mesmo, a fim de melhor explicitar tal relação, é que se iniciará a abordagem pela contextualização do que se entende por investigação interna empresarial e, na sequência, quais as consequências jurídicas e extrajurídicas que exsurgem a partir de sua adoção ou não como conduta empresarial.

\subsection{CONCEITUANDO AS INVESTIGAÇÕES INTERNAS}

De plano, como é de se supor, imperioso se torna que se conceitue e delimite o que pode ser entendido como investigações internas empresariais e de que maneira elas aparecem no ordenamento jurídico brasileiro. Só assim será possível proceder à análise mais profunda sobre as suas consequências e, mais especificamente, sobre seus eventuais custos e benefícios. 
Em linhas gerais, as investigações internas são procedimentos de apuração de ilícitos instaurados e conduzidos pela própria pessoa jurídica afetada, sobretudo quando a ação lesiva tenha sido praticada por meio dela ou no seu interesse (BULHÕES, 2019, p. 85).

Ao contrário de procedimentos de auditoria, os quais são realizados sem a necessária presença de indícios mínimos de uma conduta ilícita e tampouco visam apurar responsabilidades, mas têm função de fiscalização e controle da estrutura e rotina empresarial (SILVA, 2018, p. 90); as investigações internas se constituem num instrumento interno de reação ao ilícito posto à disposição da empresa, principalmente como desdobramento de um programa de compliance (ou integridade) minimamente eficiente (MOOSMAYER, 2013, p. 137). O seu papel primordial, na ótica dos programas de integridade, é justamente arrecadar elementos e informações que possam ser encaminhadas pela própria empresa às autoridades públicas interessadas, numa espécie de conduta colaborativa com o Estado, ao passo que, igualmente, atendem interesses próprios da pessoa jurídica atingida.

Como pontuado por Nieto Martín (2015, p. 232), a característica preponderante das investigações internas (ou internal investigations) é servir como um instrumento de reação impulsionado pela presença de indícios ou fortes suspeitas de irregularidades no seio da empresa, os quais podem derivar, por exemplo, de canais internos de denúncia (whistleblowing) ou outras formas de comunicação da irregularidade, inclusive por meio da imprensa ou dos órgãos públicos de controle. O procedimento pode ser conduzido pela própria empresa ou por quem lhe faça as vezes e, no mais, direcionam-se à elucidação de fatos que podem resultar em responsabilização jurídico-administrativa da pessoa jurídica ou seus órgãos estratégicos de representação, estando na maior parte dos casos umbilicalmente ligado a ações delitivas vistas como úteis à empresa, como costumam ser as hipóteses de corrupção lato sensu ou do crime de cartel, por exemplo (ANTONIETTO; SILVA, 2019, p. 71).

Ademais, as investigações internas, embora tenham um caráter de apuração de condutas consumadas, se revestem, ainda assim, num desdobramento dos denominados programas de compliance, visto que estes não possuem apenas um cariz preventivo, direcionado a evitar condutas, mas também têm por função primordial a estruturação de mecanismos próprios de apuração de condutas lesivas originadas na empresa, permitindo à pessoa jurídica que possa ter em mãos material informativo capaz de colaborar com o Estado na persecução dos responsáveis.

A principal interrogação aqui - pelo menos nos limites desta pesquisa - é entender por que razões uma determinada empresa detém interesse em investigar a si própria e, na sequência, entregar as informações arrecadadas a uma autoridade pública. O pensamento padrão, nesses 
casos, talvez indicasse que a empresa poderia ter lucros e benefícios muito maiores com a ocultação dos fatos do que, efetivamente, com a instauração de um procedimento interno de investigação, desnudando eventuais atos ilícitos presentes na estrutura empresarial. A lógica da legislação brasileira, contudo, demonstra o caminho inverso.

\subsection{A MATRIZ DE RESPONSABILIDADE EMPRESARIAL E A INVESTIGAÇÃO INTERNA COMO INSTRUMENTO DE ATENUAÇÃO SANCIONATÓRIA}

Historicamente, o principal fator de mudança na lógica de atuação da pessoa jurídica diante de atos ilícitos praticados em seu interior - ao menos a norma veio nesse intuito - foi o advento da Lei n. 12.846/2013, também denominada Lei Anticorrupção. A partir da previsão de responsabilização objetiva das pessoas jurídicas envolvidas em atos lesivos à administração pública, por meio da qual as empresas podem estar sujeitas às rígidas sanções administrativas e jurídicas trazidas pela norma - inclusive sequer é necessário que se demonstre a efetiva ciência por parte dos representantes legais e dirigentes acerca da prática do ato ilícito -, passou a ser do interesse da empresa a adoção de medidas que, de alguma forma, culminem na atenuação de tal carga punitiva (SILVA, 2018, p. 84).

Como recordam Gabardo e Castella (2015, p. 139), as previsões sancionatórias contidas na Lei Anticorrupção, se analisadas detidamente, permitem concluir que o âmbito de responsabilidade da pessoa jurídica ali estampado pode se apresentar num grau de severidade muito maior do que aquele inaugurado pela Lei de Crimes Ambientais, até hoje a única hipótese de responsabilização penal da pessoa jurídica no ordenamento pátrio. Além de prever a responsabilização objetiva do ente coletivo - o que no âmbito criminal é inadmissível -, a Lei Anticorrupção traz um rol sanções jurídicas de sensível gravidade, inclusive prevê a possibilidade de encerramento definitivo das atividades da pessoa jurídica em determinados casos, situação, por exemplo, que não encontra paralelo na Lei de Crimes Ambientais.

Dentre as modalidades de sanções arroladas na Lei Anticorrupção, já no âmbito administrativo - ou seja, aplicada pelos órgãos extrajudiciais de controle -, é possível se vislumbrar um forte rigor na imposição da pena. Além da possibilidade de aplicação de multa variável entre $0,1 \%$ (um décimo por cento) e $20 \%$ (vinte por cento) do faturamento bruto da pessoa jurídica constatado no ano anterior ao processo administrativo, também é permitido aos órgãos de controle a publicação extraordinária da condenação em meios de divulgação. 
E está última sanção de índole administrativa, talvez, seja aquela que mais possa apresentar prejuízos mercadológicos em desfavor da empresa, sobretudo sob o aspecto reputacional. Ao contrário da pena de multa, que permite readequação contábil - e no mais das vezes termina sendo repassada no preço do produto ou serviço da pessoa jurídica -, a publicação da condenação pode resultar em severos problemas na reputação de determinada empresa, ocasionando perdas em valor de mercado - principalmente para quem negocia ativos em bolsas de valores - e danos à imagem e junto ao consumidor, por exemplo. Como leciona Abduch Santos (2014, p. 163), tal modalidade de sanção é “[...] bastante significativa e pode produzir consequências mais severas para as pessoas jurídicas do que a pena pecuniária”, isso se dá, como complementa, porque "A boa reputação das empresas tem, contemporaneamente, especialmente no que tange às grandes corporações, valor econômico direto inegável". Por isso mesmo seu afastamento ou atenuação ganha especial realce na tomada de decisões empresariais, sobretudo a fim de colaborar com as autoridades.

Mas não só. No âmbito judicial, como já apontado, as sanções apresentadas acabam se constituindo numa das formas mais severas de punição da pessoa jurídica no ordenamento jurídico brasileiro. Dentre as penas possíveis, tem-se não só a possibilidade de condenação à reparação do dano causado, mas igualmente o perdimento de bens ou valores que sejam vistos como proveito ou produto da ação ilícita; suspensão parcial ou total das atividades empresariais e, o que é mais grave, a dissolução da pessoa jurídica se demonstrado, por exemplo, que foi constituída para fins ilícitos ou habitualmente seja utilizada para tal intento. Por último, e tal ponto tem relevância para empresas que têm por atividade-fim a prestação de serviços públicos mediante remuneração do Estado ou dependam sobremaneira de financiamentos de instituições públicas, a lei prevê a possibilidade de proibição de incentivos, subsídios, subvenções, doações ou empréstimos de órgãos ou empresas públicas à pessoa jurídica condenada.

Desse contexto, em específico, emerge o interesse da pessoa jurídica envolvida adotar posturas voltadas à redução do espectro de responsabilização da norma, principalmente no intuito de manter vivo seus vínculos com o poder público ou o acesso aos seus mecanismos de fomento. A possibilidade real e concreta de perda de incentivos e demais subsídios dirigidos pelo Estado ou por suas instituições ou, por exemplo, as repercussões comerciais advindas de uma divulgação de eventual condenação, para ficar em dois casos de relevância, já seriam suficientes a despertar nos dirigentes da pessoa jurídica um novo fator preponderante na adoção de meios de atenuação punitiva (SAAD-DINIZ; SILVEIRA, 2015, p. 317).

E é aqui que ganha relevo a figura da investigação interna. 
A Lei Anticorrupção, em especial no seu artigo $7^{\circ}$, cuida de elencar circunstâncias que devem ser sopesadas no momento de aplicação de eventual sanção às pessoas jurídicas responsabilizadas. São nove circunstâncias tanto de índole objetiva quanto de caráter subjetivo que podem levar à redução das responsabilidades ou, como diz Guimarães (2014, p. 147), “o que se deve promover, então, na avaliação das nove circunstâncias, é uma aproximação à ideia de fixação da pena base no Direito Penal, nos moldes do art. 59 do Código Penal". Dentre essas circunstâncias, nota-se que dois critérios de análise se pautam na verificação de condutas que possam demonstrar o compromisso da empresa com a prevenção de novos atos ilícitos, o que se daria com um programa de compliance efetivo, e principalmente por meio da adoção de instrumentos próprios de apuração da conduta, deixando claro que o seu interesse com o Estado não é ocultar os desvios de conduta que ocorreram em seu interior, mas colaborar com a elucidação do fato e, sobretudo, auxiliar na individualização dos sujeitos envolvidos nas ações.

O meio de apuração de condutas pela empresa, por excelência, é a investigação interna.

Mas a investigação interna, na moldura da Lei Anticorrupção, não ganha relevo apenas no que concerne à fixação da sanção, servindo com circunstância de dosagem da reprimenda num grau menor. Ela, em efetivo, pode assumir um papel de maior destaque se consideradas as possibilidades de afastamento da responsabilidade por intermédio de uma conduta colaborativa com o Estado. Pela sua característica de arrecadação de informações e elementos informativos cruciais para a compreensão do funcionamento interno da estrutura empresarial e na reconstrução do ato ilícito, é interesse tanto do Estado quanto da empresa a instauração do procedimento de investigação interna, máxime pelos benefícios maiores que poderá conceder à pessoa jurídica.

É nesse panorama que emergem os denominados acordos de leniência.

\subsection{A INVESTIGAÇÃO INTERNA COMO PRESSUPOSTO DO ACORDO DE LENIÊNCIA}

A Lei Anticorrupção, como dito, não apenas previu a possibilidade de fixação de uma pena menor à pessoa jurídica pela verificação de condutas preventivas e reativas diante de atos ilícitos, como igualmente trouxe a possibilidade de se costurar um acordo entre o Estado, por meio de seus órgãos de controle, e a pessoa jurídica a fim de elucidar os fatos em apuração de maneira mais efetiva e com o maior número de informações relevantes. 
Sempre pertinente recordar que as pessoas jurídicas de maior relevância econômica e social se estruturam em mecanismos complexos de divisão de trabalho. É comum se observar, em seus estatutos organizacionais, a construção das estruturas empresariais em relações horizontais, com diversas pessoas no mesmo patamar hierárquico e com cargos de tomada de decisões e direção em áreas estratégicas - um exemplo disso são as figuras das diretorias -; assim como se pode observar a existência de relações verticais de trabalho, então caracterizadas pela intensa delegação de funções aos mais diversos estratos da organização empresarial. Como pontuam Antonietto e Silva (2019, p. 64), no âmbito das grandes corporações empresariais, "Muitas vezes a prática de um delito estará disseminada nos meandros da organização, tornando-se difícil, ou até impossível, identificar com clareza e precisão as etapas de planejamento e execução".

E em casos nos quais a investigação do ato ilícito torna-se demasiadamente complexo principalmente pela dificuldade de se reproduzir a estrutura organizacional da empresa -, é de interesse do Estado fornecer à pessoa jurídica envolvida um extenso rol de benefícios e incentivos dirigidos a fomentar a implementação de programas de leniência em sua estrutura. A lógica nesses casos, como indica Athayde (2019, p. 31), se ampara na base da lógica da cenoura e do bastão. Ou seja, deve-se indicar aos possíveis colaboradores - no caso as pessoas jurídicas - que os eventuais benefícios oriundos da postura colaborativa podem ser oferecidos a todos aqueles que tenham envolvimento com o ato ilícito e, nesse contexto, melhores condições terá aquele que mais rapidamente assume o compromisso com o Estado, ou seja, joga-se primeiro a "cenoura". Caso contrário, poderão ser submetidos a sanções mais pesadas e infamante se comparados àqueles que colaboraram, quando então entra a lógica do "bastão".

Mas para a feitura do acordo de leniência, como é de se esperar, não basta que a pessoa jurídica simplesmente assuma a culpa pelos fatos ilícitos em apuração. É preciso muito mais. É necessário que o material apresentado tenha elementos suficientes para indicar quem são os indivíduos responsáveis, na estrutura empresarial, pelo planejamento, gestão e execução da atividade ilícita, detendo a colaboração efetividade mínima para alcançar a esfera de responsabilização individual das pessoas físicas envolvidas no ato. A arrecadação de informações, pois, é o foco principal do "negócio processual”. Como explica Bertoncini (2014, p. 204), "Se essas finalidades não forem passíveis de serem alcançadas, o acordo de leniência não poderá ser celebrado e, se celebrado, sem que possa atingir esses fins, deverá ser declarado inválido por desvio de finalidade".

É especificamente nesse contexto que ganha especial relevo a figura da investigação interna. Como se pode supor, por ser um mecanismo interno e conduzido pela própria pessoa 
jurídica afetada, a sua utilização tem grande importância como pressuposto à celebração de um acordo de leniência, por exemplo, e talvez seja esse o fator decisivo no momento de se optar pela instauração da investigação interna. Ora, se é preciso arrecadar informações e elementos a ponto de tornar a colaboração da pessoa jurídica atrativa ao Estado, nada melhor do que ela própria conduzir o processo de apuração. A uma porque saberá onde encontrar as informações, pois é a principal conhecedora da estrutura empresarial. A duas porque a apuração interna, no mais das vezes, pode evitar a divulgação massiva das ilicitudes constatadas na empresa, algo a que poderia estar suscetível em casos de deflagração, a título ilustrativo, de uma operação policial na sua sede. Logo, ao mesmo tempo que servem ao Estado, para fins de responsabilização, servem à empresa, como meio de manter hígida sua reputação no mercado (MONTIEL, 2013, p. 253-254).

Porém, é importante dizer, na moldura da Lei Anticorrupção brasileira, ao menos naquilo que se encontra positivado, não há a previsão de exclusão total da responsabilidade da pessoa jurídica. Muito longe disso. Além de não desobrigar a pessoa jurídica de reparar o dano, a celebração - e homologação - do acordo apenas tem o condão de reduzir a pena pecuniária a ser aplicada pelo Juízo, o afastamento da publicação da condenação e, por fim, a proibição de receber incentivos e financiamentos de instituições públicas ou do próprio Estado (MARRARA, 2015, p. 520-522). Isso, por óbvio, não impede que a pessoa jurídica encete outros acordos de leniência - e a lei brasileira prevê diversas modalidades deles - a fim de buscar uma melhor "blindagem" em casos de responsabilidade.

De todo modo, são nessas condições - para os casos abrangidos pela lei anticorrupção - que os gestores da pessoa jurídica deverão se pautar no momento de analisar os custos e benefícios e, por conseguinte, a eficiência de assumirem a postura colaborativa, sendo tais parâmetros possíveis de enfrentamento pela Análise Econômica do Direito.

\section{A ADOÇÃO DA INVESTIGAÇÃO INTERNA E A ESCOLHA EFICIENTE: O OLHAR DA ANÁLISE ECONÔMICA DO DIREITO}

Partindo-se, pois, de tudo o quanto foi exposto, seja em relação às premissas da AED, seja naquilo que toca às nuances e especificidades do procedimento de investigação interna, sobretudo no âmbito da Lei Anticorrupção; é que se realizará, nessa parte da pesquisa, o exame da adoção dos mecanismos internos de investigação e se, de alguma forma, se constituem numa 
escolha que atenda aos critérios de eficiência sob a ótica dos métodos econômicos de análise jurídica. Como pontuado alhures, o critério de eficiência adotado aqui será aquele conhecido como Kaldor-Hicks, em que a eficiência ocorre quando os benefícios de uma conduta superam os seus custos.

Pois bem.

Sob a ótica da investigação interna e, sobretudo, dos acordos de leniência - o seu principal fim se observada a partir da Lei Anticorrupção - algumas questões merecem destaque. A primeira delas, como destacado por Marrara (2015, p. 513), se refere aos custos do procedimento. A investigação interna, visando o acordo de leniência, será custeado integralmente pela pessoa jurídica envolvida e não contará com o auxílio estatal. Mas não só. É preciso também destacar que a opção pela investigação interna e, por conseguinte, dos programas de leniência, deixam a pessoa jurídica à mercê de eventuais acusações por parte de outros órgãos de controle que não estejam elencados entre as partes do acordo. É dizer: embora esteja colaborando com as autoridades públicas, a pessoa jurídica não se torna imune a eventuais processos administrativos originados em outros entes integrantes dos mecanismos de controle do poder público. Ou seja, ao mesmo tempo que atenua responsabilidades num campo, poderá dar elementos à responsabilização em outros.

Em suma, os custos podem ser elencados como aqueles decorrentes da instauração do procedimento e da assunção do risco de acusação noutras esferas administrativas.

Ribeiro e Diniz (2015, p. 94) assim resumem:

\begin{abstract}
De forma resumida, os custos de transação para a implantação de uma política de Compliance se dividem em três aspectos: custos de manutenção, de não conformidade e de governança. Em relação ao primeiro, estão abrangidos os custos para executar e promover essa política, como custo de pessoal, treinamento, comunicação e consultoria; no que se refere aos custos de não conformidade, podem-se citar as penalidades, multas e tributos, custo de remediação, perda da receita, interrupção dos negócios e perda da produtividade, impacto no capital, danos à reputação da empresa, de seus empregados e da marca, despesas com advogados, custas judiciais e valor/hora da alta administração; por fim, quanto aos custos de governança, essencial para tal implantação, têm-se a manutenção e as despesas da diretoria e dos comitês, custos legais e jurídicos, contratação de auditoria externa e relacionamento com investidores e comunicações.
\end{abstract}

Porém, sob a ótica dos benefícios, a pessoa jurídica também conta com fortes elementos de incentivo à adesão da persecução privada do ilícito.

Em primeiro plano, tem-se que a assunção de condutas positivas por parte da empresa, a fim de investigar e punir o ilícito, deixa uma marca indelével no mercado. A existência de 
uma cultura de persecução da ilicitude evita - ou pelo menos atenua - os denominados danos reputacionais. Como pontuam Ribeiro e Diniz (2015, p. 93), “Um dos maiores riscos externos que o Compliance pretende minorar é a quebra da reputação, pois sua perda provoca 'publicidade negativa, perda de rendimentos, litígios caros, redução da base de clientes e, nos casos mais extremos, até a falência"”. Com efeito, a investigação interna, por ser parte de um programa de integridade minimamente eficiente, se presta a resgatar na lógica de mercado a reputação de uma empresa, demonstrando ao público e aos investidores, um compromisso com a legalidade e com a responsabilização dos indivíduos que praticaram o ato ilícito. Ganham com isso não só o empresariado, mas o próprio Estado, pois passa a imagem de transparência e respeito às regras do jogo da economia.

Ademais, a instauração do procedimento de investigação interna, para além dos limites da Lei Anticorrupção, permite a celebração de acordos de leniência sob outras esferas jurídicolegais, amparando uma maior blindagem da empresa aos efeitos da responsabilização, podendo, inclusive, haver uma quase isenção em alguns pontos. Mas, como descreve Marrara (2015, p. 514), a leniência decorrente da investigação interna gera uma obrigação de redução nas sanções por parte do Estado, mas, por evidente, também resulta em uma obrigação por parte da empresa em obter material suficiente a satisfazer o interesse do Estado na obtenção da prova e na arrecadação de elementos capazes de gerar um resultado útil em eventual processo administrativo ou judicial. De todo modo, um comprometimento com as atividades do Estado demonstrado pela seriedade do procedimento de investigação interna gera o dever por parte do poder público em reduzir o espectro da responsabilidade do ente privado.

Mas existe outro ponto que deve sopesar a escolha eficiente: o consumidor crítico. Num contexto de forte senso crítico nos consumidores - e também de investidores - a publicização de um comportamento comprometido com a contenção dos atos ilícitos gera uma imagem positiva e sustentável de determinada empresa no mercado (RIBEIRO; DINIZ, 2015, p. 94).

Assim, numa síntese de tudo o quanto exposto, sob a ótica da AED, a adoção de mecanismos de investigação interna - então decorrentes de programas de Compliance - embora traga consigo custos de implementação, como, por exemplo, gasto na contratação de profissionais especializados na sua condução e a possibilidade de responsabilização em outras esferas; geram também benefícios bastante atrativos sob a ótica do mercado. A partir da possibilidade de minimização - ou quase exclusão - de danos reputacionais, que interferem diretamente no valor de mercado da empresa e na sua imagem com uma imensa gama de consumidores conscientes e críticos, e principalmente da possibilidade de atenuação de parcela das responsabilidades jurídico-administrativas - e no caso de empresas que tenham como 
atividade-fim a contratação pelo Estado isso tem maior sensibilidade -, nota-se que a pessoa jurídica tem mais a ganhar do que a perder com a assunção de uma posição colaborativa.

Como já aventado anteriormente, a aceitação da "cenoura", como dito por Athayde (2019, p. 31), afasta e muito os efeitos da "dor" oriundos do uso do "bastão" por parte do Estado, notadamente sob uma nova matriz de responsabilidade objetiva, em que sequer a culpa é preciso para a punição.

\section{CONSIDERAÇÕES FINAIS}

O escopo desse trabalho, desde sua origem, foi apurar em que medida as investigações internas empresariais se relacionam com a Análise Econômica do Direito e, nos limites da pesquisa, é de se ver que houve a resposta a tal indagação.

Como exposto, a AED tem por finalidade usar a teoria econômica como referencial analítico das decisões adotadas na esfera jurídica, servindo, assim, como mecanismo interdisciplinar de análise das ciências jurídicas. Longe de simplesmente pretender transpor as categorias econômicas aos institutos jurídicos, a AED tem por premissa o enfrentamento da eficiência no direito a partir de ferramentas epistemológicas derivadas do estudo conjunto entre as ciências econômicas e as ciências jurídicas. Dessa compreensão, a partir dos critérios de Kaldor-Hicks, uma decisão individual somente poderá ser vista como eficiente, principalmente no aspecto jurídico, se os seus custos forem menores do que seus benefícios, tornando a escolha de tal ou qual caminho mais atrativa aos interesses do sujeito racional, o mesmo sujeito que tem por base o atendimento, em todas as circunstâncias, daquilo que melhor atenda suas pretensões individuais.

Isso, por evidente, não permitirá a adoção do caminho mais justo, posto que justiça integra um conceito aberto e subjetivo, passível de interpretação pessoal, mas, por outro lado, permite saber desde logo qual caminho será o injusto posto que não possibilitará os melhores benefícios e, portanto, não será visto como eficiente. E se é ineficiente, nos termos da AED, seguramente não será adequado aos critérios de justiça.

Dentro desse panorama, pois, buscou-se o estudo específico do fenômeno das investigações internas, notadamente sob o aspecto posto pela Lei anticorrupção. Como se infere do presente trabalho, as investigações internas culminam na adoção pela própria empresa, de condutas de persecução do ilícito praticados no seu interesse, o que, ao final, instruirá um 
procedimento jurídico ou administrativo conduzido por uma autoridade pública. A grande questão, nesse diapasão, era saber por qual motivo uma empresa adotaria uma postura colaborativa a fim de elucidar um ato ilícito cometido por ela própria, enquanto entidade, ou no seu interesse próprio.

A resposta, como se viu, veio a partir da AED.

Considerando os benefícios oriundos da Lei Anticorrupção, sobretudo pela feitura de acordos de leniência, a conduta colaborativa da empresa esboçada na instauração de uma investigação própria faz com que a pessoa jurídica tenha mais a ganhar do que a perder. A começar pelos danos reputacionais, talvez mais sensíveis no âmbito do mercado, e passando pela possibilidade de atenuação e eventual blindagem de certas esferas de responsabilidade, o acordo de leniência firmado com base numa investigação interna séria e efetiva apresenta-se como uma decisão que melhor atende aos critérios de eficiência fixados pela AED.

Destarte, nota-se que as investigações internas, em especial aquelas dirigidas à celebração de acordos de leniência, são mecanismos diretamente vinculados à ideia de eficiência na adoção de uma conduta por parte dos indivíduos racionais e, nessa toada, são instrumentos umbilicalmente ligados aos preceitos fixados pela dita Análise Econômica do Direito.

\section{REFERÊNCIAS BIBLIOGRÁFICAS}

ALVAREZ, Alejandro Bugallo. Análise econômica do direito: contribuições e desmistificações. Revista Direito, Estado e Sociedade, v. 9, n. 29, p. 49-68, 2006.

ANTONIETTO, Caio Marcelo Cordeiro; SILVA, Douglas Rodrigues da. Aproveitamento de investigações internas como prova no processo penal. Revista Brasileira de Ciências Criminais, São Paulo, ano 27, n. 156, p. 61-90, jun. 2019.

ATHAYDE, Amanda. Manual dos acordos de leniência no Brasil: teoria e prática. Belo Horizonte: Fórum, 2019.

BERTONCINI, Mateus. Capítulo V - do acordo de leniência: comentários aos artigos 16 e 17. In: CAMBI, Eduardo; GUARAGNI, Fábio André (coord.); BERTONCINI, Mateus (org.). Lei Anticorrupção: comentários à lei n. 12.846/2013. São Paulo: Almedina, 2014. p. 189-220.

BOBBIO, Norberto. Teoria da norma jurídica. Tradução de Fernando Pavan Baptista e Ariani Bueno Sudatti. 5. ed. rev. São Paulo: Edipro, 2012. 
BORGES, Alexandre Walmott et al. A violação à ordem econômica na constituição de 1988 e à lei antitruste no exercício disfuncional da ação na defesa da propriedade intelectual. Revista Jurídica, [S.1.], v. 2, n. 47, p. 335-362, jul. 2017. ISSN 2316-753X. Disponível em: <http://revista.unicuritiba.edu.br/index.php/RevJur/article/view/2038/1317>. Acesso em: 23 abr. 2020. doi:http://dx.doi.org/10.21902/revistajur.2316-753X.v2i47.2038.

BULHÕES, Gabriel. Manual prático de investigação defensiva: um novo paradigma na advocacia criminal brasileira. Florianópolis: EMais, 2019.

GABARDO, Emerson; CASTELLA, Gabriel Morettini. A nova lei anticorrupção e a importância do compliance para as empresas que se relacionam com a Administração Pública. A\&C - Revista de Direito Administrativo \& Constitucional, Curitiba, v. 15, n. 60, p. 129-147, 2015.

GONÇALVES, Everton das Neves; STELZER, Joana. Eficiência e direito: pecado ou virtude; uma incursão pela análise econômica do direito. Revista Jurídica (UNICURITIBA), Curitiba, v. 1, n. 28, p. 77-122, 2012.

GONÇALVES, Oksandro Osdival; RIBEIRO, Marcelo Miranda. Incentivos Fiscais: uma perspectiva da Análise Econômica do Direito. Economic Analysis of Law Review, v. 4, n. 1, p. 79-102, 2013.

GUIMARÃES, Rodrigo Regnier Chemim. Capítulo III - da responsabilização administrativa: comentários aos artigos $6^{\circ}$ e $7^{\circ}$. In: CAMBI, Eduardo; GUARAGNI, Fábio André (coord.); BERTONCINI, Mateus (org.). Lei Anticorrupção: comentários à lei n. 12.846/2013. São Paulo: Almedina, 2014. p. 137-162.

HAMANN, Trent H. Neoliberalismo, governamentalidade e ética. Ecopolítica, São Paulo, n. 3, p. 99-133, 2012.

KELSEN, Hans. Teoria geral do direito e do estado. Tradução de Luis Carlos Borges. 2. ed. São Paulo: Martins Fontes, 1992.

LAUDA, Bruno Bolson. A análise econômica do direito: uma dimensão da crematística no Direito. Revista Eletrônica do Curso de Direito da UFSM, v. 4, n. 1, 2009.

MARRARA, Thiago. Acordos de leniência no processo administrativo brasileiro: modalidades, regime jurídico e problemas emergentes. Revista Digital de Direito Administrativo, v. 2, n. 2, p. 509-527, 2015.

MONTIEL, Juan Pablo. Sentido y alcance de las investigaciones internas en la empresa. Revista de derecho, Valparaíso, n. 40, p. 251-277, 2013. 
MOOSMAYER, Klaus. Investigaciones internas: una introducción a sus problemas esenciales. In: ARROYO ZAPATERO, Luis; NIETO MARTÍN, Adán (dir.). EI derecho penal económico en la era compliance. Valencia: Tirant Lo Blanch, 2013. p. 137-143.

NIETO MARTÍN, Adán. Investigaciones internas, In. NIETO MARTÍN, Adán et al. Manual de cumplimiento penal en la empresa. Valencia: Tirant Lo Blanch, 2015. p. 231-270.

RIBEIRO, Gustavo Ferreira; CAIADO, Jose Guilherme Moreno. Por que uma análise econômica do direito internacional público? desafios e perspectivas do método no Brasil. Revista de Direito Internacional, Brasília, v. 12, n. 2, 2015 p. 245-261

RIBEIRO, Marcia Carla Pereira; CAMPOS, Diego Caetano da Silva. Análise econômica do direito e a concretização dos direitos fundamentais. Revista Direitos Fundamentais \& Democracia, Curitiba, v. 11, n. 11, p. 304-329, 2012.

RIBEIRO, Marcia Carla Pereira; DINIZ, Patrícia Dittrich Ferreira. Compliance e lei anticorrupção nas empresas. Revista de informação legislativa, Brasília, v. 52, n. 205, p. 87$105,2015$.

SAAD-DINIZ, Eduardo; SILVEIRA, Renato de Mello Jorge Silveira. Compliance, direito penal e lei anticorrupção. São Paulo: Saraiva, 2015.

SANTOS, José Anacleto Abduch. Capítulo III: da responsabilização administrativa. In: SANTOS, José Anacleto Abduch; BERTONCINI, Mateus; COSTÓDIO FILHO, Ubirajara. Comentários à lei n. 12.846/2013: lei anticorrupção. São Paulo: Editora Revista dos Tribunais, 2014. p. 157-190.

SILVA, Douglas Rodrigues da. Compliance: a investigação interna e seus limites. In: GIONÉDIS, Louise Rainer Pereira; VIANNA, Maria Amélia Cassiana Mastrorosa (org.). Compliance e a nova realidade empresarial. Curitiba: Instituto Memória, 2018. p. 77-101.

TABAK, Benjamin Miranda. A análise econômica do direito: proposições legislativas e políticas públicas. Revista de Informação Legislativa, Brasília, v. 52, n. 205, p. 321-345, 2015.

VIEIRA, Antônio Rufino. A filosofia marxiana: uma análise das teses de Marx sobre Feuerbach. Princípios: Revista de Filosofia (UFRN), Natal, v. 3, n. 04, p. 27-50, 1996. 